УДК 551.465

\author{
О ВОЗМОЖНОСТИ ПРИСУТСТВИЯ КИСЛОРОДА \\ В ВЕРХНЕМ СЛОЕ ОСАДКОВ \\ СЕРОВОДОРОДНОЙ ЗОНЫ ЧЕРНОГО МОРЯ \\ (С) 2019 г. П.А. Стунжас ${ }^{1}$, М.Б. Гулин ${ }^{2}$, А.Г. Зацепин ${ }^{1}$, Е.А. Иванова ${ }^{2}$ \\ ${ }^{1}$ Институт океанологии им. П.П. Ширшова РАН, Москва, Россия \\ ${ }^{2}$ Институт морских биологических исследований им. А. О. Ковалевского РАН, Севастополь, Россия \\ e-mail: pastunzhas@mail.ru \\ Поступила в редакцию 08. 11. 2017 г.

\begin{abstract}
В северо-восточной части Черного моря произведен поиск в гипоксийных и аноксийных условиях живых организмов эукариот (микро- и мейозообентоса), а также измерение О2 в придонном слое воды и в верхнем слое осадков.Результаты показывают наличие глубинного максимума численности зообентоса в диапазоне глубин 215-244 м. Данное скопление бентосной фауны охватывает повертикали слой в 30 м. В целом, доля активного мейобентоса не превышала $1.5 \%$ от общего числа обнаруженных в пробе организмов. Наличие аэробного бентоса в районе верхней границы $\mathrm{H}_{2} \mathrm{~S}$ можнообъяснить: сползанием осадков с меньшей глубины; квазипериодической поставкой $\mathrm{O}_{2}$ за счет колебания положения изопикн и/или опускания вод вдоль склона в придонном экмановском слое. Также, при физическом поступлении в придонный слой кислорода, он сравнительно долго может сохраняться в верхней части зоны $\mathrm{H}_{2} \mathrm{~S}$ в виду отсутствия глубинного потока $\mathrm{Mn}^{+2}$ и реакции с ним.
\end{abstract}

Ключевые слова: редокс-хемоклин, сероводородная зона, аэрация донных отложений, глубинное скопление зообентоса, Чёрное море

DOI: https://doi.org/10.31857/S 0030-157459166-169

В июне-июле 2015 и 2017 гг. в северо-восточной части Черного моря проводились исследования возможности проникновения $\mathrm{O}_{2}$ в верхние слои $\mathrm{H}_{2} \mathrm{~S}$-зоны, в области контакта периферийных границ хемоклина со склоном дна. Исследования имели два направления: поиск в гипоксийных и аноксийных условиях живых организмов эукариот (микро- и мейозообентоса), а также измерение $\mathrm{O}_{2}$ в придонном слое воды и в верхнем слое осадков. Оба направления при измерениях сочетались.

Бентосные съемки производились на траверзе Геленджикской бухты - в районе гидрофизического полигона ИО РАН и расположения заякоренной буйковой станции с зондом-профилографом «Аквалог» [4], с борта БПМ-74 «Ашамба». Использовался грунтоотборник (трубка) «Румолот» производства ИМБИ, снабженный прозрачной акриловой трубкой с толщиной стенок 3 мм, внутренним диаметром 54 мм и высотой 30 см. Трубка вставляется в носитель из железобетона весом 16 кг с крепежной арматурой. На верхнем торце трубки расположен клапан с заслонкой из пластика с резиновым кольцевым уплотнителем, который имеет слабую отрицательную плавучесть. Заслонка лишена возвратной запорной пружины и закрывается при подъеме прибора под собственным весом в сочетании с напором встречного потока воды. Нижний конец трубки заострен по окружности и не содержит закупоривающего механизма, при подъеме трубки на палубу он вручную закрывается резиновой пробкой. Данная конструкция позволяет отбирать пробы преимущественно илистых грунтов. Получаемые колонки грунта сохраняют, как правило, ненарушенное строение с естественной слоистой текстурой осадка. Однако, насколько трубка предохраняет загрязнение самого осадка и воды над ним от попадания $\mathrm{O}_{2}$, пока остается неясным:

1) при подъеме трубки, если осадок плотно прилегает к стенке, диффузия $\mathrm{O}_{2}$ снизу (в нашем случае на 19 см), если там отсутствуют случайные твердые вкрапления, представляется невозможной; 
Таблица. Распределение по глубине плотности поселений мейозообентоса (экз /10 см²). Курсив - данные 2017 г.

\begin{tabular}{c|c|c|c|c|c|c|c|c|c}
\hline Глубина, м & 112 & 142 & 145 & 167 & 175 & 215 & 238 & 244 & 260 \\
Плотность & 153.9 & 6.97 & 30.96 & 0.00 & 0.08 & 0.49 & 5.23 & 9.30 & 0.00 \\
\hline
\end{tabular}

2) при спуске трубка заполняется легкой поверхностной водой с $\mathrm{O}_{2}$, которая плохо оттуда вымывается;

3) при отборе пробы не вся вода с $\mathrm{O}_{2}$ может вытесняться (а частично перемешиваться).

Численность черноморского зообентоса на больших глубинах в сравнении с верхней сублиторалью можно принять как относительно консервативный параметр. Поэтому результаты обоих съемок представлены в единой таблице. Для определения функционального состояния бентосных организмов в свежих нефиксированных образцах донных отложений на дополнительной станции с глубиной дна 240 м, в слоях грунта 0.0-0.5, 0.5-1.0 и 1-2 см (не включено в таблицу) было проведено микроскопирование осадков, что позволило выявить присутствие живых организмов в самом верхнем слое грунта - в сероводородной зоне. Главным образом, это оказались представители одноклеточных - Ciliata и мягкораковинные фораминиферы - аллогромииды. Живых Metazoa на глубине 240 м не найдено. В целом, доля активного мейобентоса не превышала $1.5 \%$ от общего числа обнаруженных в пробе организмов. Мертвая компонента составляла $92.4 \%$, определить функциональное состояние (активные живые, живые в анабиозе или мертвые организмы) остальных $6 \%$ найденных особей мейобентоса оказалось затруднительно. На иных глубинах, кроме указанной изобаты 240 м, подобные наблюдения не проводились, анализировался лишь фиксированный материал (табл.).

Результаты хорошо согласуются с данными более ранних исследований в западной части Черного моря $[7,8,1]$ и показывают наличие глубинного максимума численности зообентоса в диапазоне глубин 215-244 м. Данное скопление бентосной фауны охватывает по вертикали слой в 30 м. При этом в горизонтальной проекции, с учетом относительно малых углов наклона дна, он, несомненно, является гораздо более протяженным.
Одновременно проводились гидрологические съемки зондом SBE-19-plus с кассетой батометров.

2015 г. Над склоном с глубинами 199-263 м наличие растворенного кислорода в пробах придонной воды было найдено вплоть до глубины 142 м (0.39 mg/l). Для этого сразу после подъема CTD-зонда сенсор оксиметр-оптода LDO-HACH-HQ10d опускали в нижнюю часть батометра через его приоткрытую крышку. Изопикна 16.2, обычно соответствующая глубине залегания верхней границы сероводородной зоны, располагалась сравнительно глубоко - на горизонте 166-174 м.

2017 г. Зонд SBE был дополнен оксиметром-оптодом производства ЦАГИ (г. Жуковский) [6]. Над склоном с глубинами 110-300 м нижний горизонт проникновения растворенного кислорода фиксировался на глубине 115-120 м. В то же время верхняя граница зоны H2S (изопикны 16.2) была на глубине 136-140 м. Известно, что на склоне заглубление изопикн происходит при развитом Основном черноморском течении (ОЧТ), а их подъем, соответственно, при его ослаблении, что характерно для летних месяцев. Так что в 2015 г. съемка проходила при более развитом ОЧТ, чем в 2017 г. По данным зонда «Аквалог», в период 2013-2014 гг. вертикальные колебания глубины изопикны 16.2 происходили в интервале глубин 125-215 м, с преобладающим залеганием на горизонте 155-175 м [4].

Для анализа $\mathrm{O}_{2}$ в осадках был апробирован новый лабораторный оксиметр-оптод PreSens производства фирмы $\mathrm{GmbH}$ (Германия). В нем свет возбуждения и люминесцентного отклика передаются по тонкому световоду, так что его чувствительный элемент (spot 3), представляющий тонкий кружок Д=4 мм, клеится на внутреннюю поверхность сосуда (трубка «Румолот»), и определение $\mathrm{O}_{2}$ производится без открывания трубки. В нашем случае спот был наклеен на высоте 19 см от нижнего края трубки. 
Особо проверялась пригодность оптода для целей работ. По паспорту спот 3 работает с концентрациями $\mathrm{O}_{2}$ ниже 20 мг/л, и имеет динамический диапазон 200, т.е. его точность составляет примерно 0.1 мг/л, что в нашем случае явно недостаточно. Но, так как при низком $\mathrm{O}_{2}$ сигнал люминесценции максимальный, имелась надежда, что реальная точность будет выше. Калибровка в сосуде, заполненном аргоном чистоты $99.98 \%$, показала, что точность спота составляет примерно \pm 15 мкг/л, т.е. реальный динамический диапазон составляет примерно 600, и завышение «нуля» примерно на 25 мкг/л.

Как видно из табл. в 2017 г. удалось взять только 2 трубки с осадком с глубин 215 и 238 м. В первом случае спот оказался в осадке на глубине 2 см и показал (с учетом поправки) концентрацию $\mathrm{O}_{2} 25 \pm 15$ мкг/л, во втором - на глубине 6 см: $50 \pm 15$ мкг/л. С одной стороны, такой результат подтверждает данные бентосных измерений, причем в точке с более высокой концентрацией бентоса найдена более высокая концентрация $\mathrm{O}_{2}$. Но чисто формально первый результат (т.е. что $\mathrm{O}_{2}>0$ ) недостоверен, второй - достоверен, но вызывает вопросы. Как показывают измерения $\mathrm{O}_{2}$ в осадках Черного моря, кислород обычно наблюдают только в верхнем слое толщиной менее 1 см [1], потому присутствие его на глубине 6 см, скорее всего, является или артефактом (возможности загрязнения проб $\mathrm{O}_{2}$ упоминались выше) или случайным. Таким образом, по нашим измерениям нельзя достоверно сказать, что мы нашли присутствие $\mathrm{O}_{2}$ в точках отбора проб осадка.

Тем не менее, как нам кажется, наличие аэробного бентоса в районе верхней границы $\mathrm{H}_{2} \mathrm{~S}$, причем с резко очерченной нижней границей (в интервале глубин всего 15 м; табл.), объяснить можно. Кратко упомянем разные гипотезы. Механическая: сползание осадков с меньшей глубины, хотя обнаруженный глубинный пик численности зообентоса - это не первый случай такого рода наблюдений [7, 1]. Физическая: квазипериодическая поставка $\mathrm{O}_{2}$ за счет колебания положения изопикн [4] и/или опускания вод вдоль склона в придонном экмановском слое [2]. Химическая: при физическом поступлении в придонный слой кислорода, он сравнительно долго может сохраняться в верхней части зоны $\mathrm{H}_{2} \mathrm{~S}$ в виду отсутствия глубинного потока $\mathrm{Mn}^{+2}$ и реакции с ним.
В то же время находки мейобентоса на глубинах более 400 м (см., например, [3, 5]) противоречивы и требуют изменения устоявшихся представлений о происходящих в Черном море процессах, поэтому они пока останутся вне поля зрения наших исследований.

Источник финансирования. Работа выполнена при финансовой поддержке РФФИ №17-05-00381. Также, исследования были поддержаны финансированием по теме государственного задания ФГБУН ИМБИ «Функциональные, метаболические и токсикологические аспекты существования гидробионтов и их популяций в биотопах с различным физико-Химическим режимом», № гос. регистрации АААА-A18-118021490093-4.

\section{СПИСОК ЛИТЕРАТУРЫ}

1. Гулин М.Б. Батиметрическое распределение живых активных форм зообентоса в хемоклине Черного моря // Морской экологический журнал. 2013. Т.12. № 1. С. 5-17.

2. Елкин Д.Н., Зацепин А.Г., Подымов, О.И., Островский А.Г. Опускание вод в экмановском слое, образованном прибрежным даунвеллинговым течением над наклонным дном // Океанология. 2017. Т. 57. № 4. С. 531-537.

3. Зайцев Ю.П., Аниупова Л.В., Воробьева Л.В. $u \partial p$. Нематоды в глубоководной зоне Черного моря // Докл. АН УССР. Сер. Б. 1987. № 11. С. 77-79.

4. Зацепин А.Г., Островский А.Г., Кременецкий В.В. $u \partial p$. Подспутниковый полигон для изучения гидрофизических процессов в шельфо-склоновой зоне Черного моря // Физ. атмосф. и океана. 2014. №1. С.16-29.

5. Сергеева Н.Г. К вопросу о биологическом разнообразии глубоководного бентоса Черного моря // Экология моря. 2000. Вып. 50. С. 57-62.

6. Стунжас П.А., Мошаров В.Е., Радченко В.Н. Возможности фотолюминесцентного метода измерения концентрации кислорода в редокс зоне Черного моря в сравнении с другими методами // Океанология. 2013. Т. 53. № 4. С. 507-516.

7. Luth U., Luth C.M. A benthic approach to determine long-term changes of the oxic/ anoxic interface in the water column of the Black Sea / Proc. 30th Europ. Mar. Biol. Symp. (Southampton, UK, Sept 1995). Southampton, 1997. P. 231-242.

8. Sergeeva N.G., Gulin M.B. Meiobenthos from an active methane seepage area in the NW Black Sea // Marine Ecology an Evolutionary Perspective, Special topics volume 'Ecology and evolution of vent, seep and whalefall organisms'. 2007. V. 28. 1. P. 152-159. 


\title{
On the Possible Presence of Oxygen in the Upper Sediment Layer of the Hydrogen Sulfide Zone in the Black Sea
}

\author{
(C) 2019 P. A. Stunzhas' ${ }^{1}$ M. B. Gulin ${ }^{2}$, A. G. Zatsepin'1, E. A. Ivanova ${ }^{2}$ \\ ${ }^{1}$ Shirshov Institute of Oceanology, Russian Academy of Sciences, Moscow, Russia \\ ${ }^{2}$ Kovalevsky Institute of Marine Biological Research Russian Academy of Sciences, Sevastopol, Russia \\ e-mail: pastunzhas@mail.ru \\ Received November 8, 2017
}

In the northeastern Black Sea the search was performed for living eukaryotic organisms (micro- and meiobenthos) in hypoxic and anoxic conditions as well as measurement of $\mathrm{O} 2$ in the bottom water layer and in the upper layer of sediments. The results have shown the presence of a deep maximum abundance of zoobenthos in a depth range of 215-244 m. This aggregation of benthic fauna occupies a layer of $30 \mathrm{~m}$ along the vertical. In general, the proportion of active meiobenthos was no greater than $1.5 \%$ of the total number of organisms recorded from the sample. The presence of aerobic benthos near the upper boundary of the $\mathrm{H} 2 \mathrm{~S}$ zone can be explained by: sliding down of sediments from a higher depth; quasi-periodic $\mathrm{O} 2$ supply due to fluctuations in the position of the isopycna and/or sinking of waters downslope in the bottom Ekman layer. Also, in the case of physical entry of oxygen into the bottom layer, it can remain for a relatively long time in the upper part of the $\mathrm{H} 2 \mathrm{~S}$ zone due to the lack of deep $\mathrm{Mn}+2$ flux and reaction with it.

Keywords: redox-chemocline, H2S zone, aeration of seabed sediments, deep-sea layer of zoobenthos, Black Sea 